\title{
Azaphosphatranes Catalyzed Strecker Reaction in the Presence of Water
}

\author{
Jian Yang, ${ }^{[\mathrm{a}]}$ Anne-Doriane Manick, ${ }^{[\mathrm{a}]}$ Chunyang Li, ${ }^{[\mathrm{a}]}$ Xavier Bugaut, ${ }^{[\mathrm{a}]}$ Bastien Chatelet, ${ }^{[\mathrm{aa}]}$ \\ Véronique Dufaud ${ }^{[b]}$ Damien Hérault, ${ }^{*[a]}$ and Alexandre Martinez ${ }^{*[a]}$
}

Azaphosphatranes were found to act as efficient organocatalysts in the presence of water for the cyanation of differently substituted imines. A relatively safer source of cyanide, trimethylsilyl cyanide (TMSCN), was used, and excellent yields could be obtained with only $0.05 \mathrm{~mol} \%$ of catalyst. The influence of acidity of azaphosphatranes on catalytic activity as well as the role of azaphosphatranes in the mechanism of the reaction were also investigated.

Azaphosphatranes are the protonated counterparts of the proazaphosphatranes (Verkade's superbases) described by J. G. Verkade in 1989 (Figure 1). ${ }^{[1]}$ In contrast to proazaphosphatranes, which have been widely studied in organic transformations as non-ionic bases or organocatalysts, ${ }^{[2,3]}$ and also as ligands in metal-catalyzed reactions, ${ }^{[4]}$ their protonated analogues have attracted much less interest. In 1999, the Verkade group first used azaphosphatranes as procatalysts in dehydrohalogenations and debrominations in the presence of sodium hydride. ${ }^{[5]}$ Later, the same group described the ability of these species to catalyze the aza and thia-Michael reactions as well as the Strecker reaction. ${ }^{[6]}$ Benefiting from the robustness and hydrophobicity of these azaphosphatrane cations, our group employed them as phase transfer catalysts for the alkylation of enolates, generation of carbene and oxidation of an electrophilic alkene. ${ }^{[7]}$ More recently, we have demonstrated that they also can act as effective catalysts in lactide ring-opening polymerization, ${ }^{[8]}$ and in the synthesis of cyclic carbonates from epoxides and $\mathrm{CO}_{2}$. In both cases, activity efficiency was found to rely on better activation of the substrates through hydrogen-bond interactions. ${ }^{[9]}$ Besides, to allow for easier recovery and recyclability and to avoid the problem of salt solubility, the immobilization of azaphosphatranes was carried out by Verkade on Merrifield resin, and by our group on mesoporous (a)
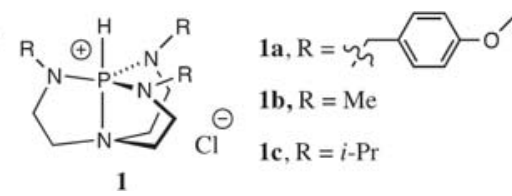

(b)

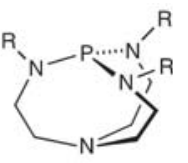

Figure 1. (a) Azaphosphatranes 1 a-c used in this study, (b) general structure of Verkade's superbases (pro-azaphosphatranes).

SBA-15 silica. $^{[10]}$ More recently, azaphosphatranes have been shown to act as subcomponents in the construction of tetrahedron cages for anion encapsulation and extraction. ${ }^{[11]}$ In addition, Johnson and co-workers studied the factors that affect transannulation in azaphosphatranes, which further shed light on this bicyclic architecture. ${ }^{[12]}$ These recent insights highlight the growing interest aroused by azaphosphatranes, to lead to new and original applications.

Strecker reaction consists of the direct cyanation of imines, a reaction of utmost importance for the synthesis of $\alpha$ aminonitriles, which are versatile building blocks in organic synthesis and present in many biologically active products. ${ }^{[13]}$ Since Adolph Strecker discovered this reaction as a direct route to access amino acids from aldehydes or ketones in 1850, different methodologies have been developed to perform this transformation. To this end, Lewis acids have been used frequently, ${ }^{[14]}$ however, tedious workup is generally required, and the generation of toxic metallic wastes hampers extensive development at the industrial scale. On the other hand, some organocatalysts ${ }^{[15]}$ such as $\mathrm{N}$-heterocyclic carbenes, ${ }^{[16]}$ guanidine hydrochloride, ${ }^{[17]}$ and thioureas ${ }^{[18]}$ have been reported to catalyze the $\alpha$-cyanation of imines, however, relatively higher catalyst loading or longer reaction times were needed to achieve satisfactory reactivity. Very recently, Zhou, Zeng et al. demonstrated that carbonyl-stabilized phosphorus ylides are remarkable catalysts for the Strecker reaction using TMSCN as cyanide source ${ }^{[19]}$ Furthermore, our group reported the use of proazaphosphatranes as organocatalysts in the Strecker reaction, displaying excellent catalytic activity with high TOFs around $10^{5} \mathrm{~h}^{-1}$ and TONs up to $10^{4}$ in only $20 \mathrm{~min}$ with $0.1 \mathrm{~mol} \%$ catalyst loading. ${ }^{[20]}$ Due to the very sensitive nature of proazaphosphatranes toward moisture and air, and taking advantage of the many benefits of the azaphosphatrane architecture in terms of stability, robustness and handling, we wished to explore their catalytic behavior in more details for the Strecker reaction. 
Herein, we report on the catalytic activity of azaphosphatranes in the Strecker reaction between imines and trimethylsilyl cyanide (TMSCN) in the presence of water. Excellent yields are achieved with only $0.05 \mathrm{~mol} \%$ catalyst in $2 \mathrm{~h}$. The influence of the acidity of azaphosphatranes on the catalytic activity was also examined and a possible reaction pathway is proposed.

The cyanation reaction was first examined on $\mathrm{N}$-tosylbenzaldimine $2 \mathrm{a}$ (1.0 equiv.) with TMSCN (1.5 equiv.) in the presence of azaphosphatrane $1 \mathrm{a}$ as catalyst $(0.1 \mathrm{~mol} \%)$ (Table 1). We were pleased to observe that, in 20 minutes and at $0{ }^{\circ} \mathrm{C}$, a yield of $90 \%$ was reached without specific purification or drying of the reaction medium (Entry 2, Table 1). It is interesting to note that the presence of water has a dramatic effect on the conversion. Indeed, with dry methylene chloride (DCM), only $17 \%$ yield was obtained (Entry 1, Table 1) while, with the solvent system $\mathrm{DCM} / \mathrm{H}_{2} \mathrm{O}: 3 / 1$ a nearly quantitative yield was achieved ( $95 \%$, Entry 3, Table 1). It is important to note that, with both solvent systems, no conversion was shown in the absence of catalyst (Entries 6-7). Using only $0.05 \mathrm{~mol} \%$ of catalyst, $61 \%$ and $99 \%$ yields were obtained after $20 \mathrm{~min}$ (Entry 4, Table 1) and after $2 \mathrm{~h}$ (Entry 5, Table 1) respectively, corresponding to TOF $>3.6 \times 10^{3} \mathrm{~h}^{-1}$ and TON around $2 \times 10^{3}$. Further insight into the role played by the azaphosphatrane moiety was obtained by testing other chlorine salts as catalysts. When $\mathrm{NaCl}$ is used instead of 1 a (Entry 9, Table 1), no product is formed, whereas the use of $\mathrm{Bu}_{4} \mathrm{NCl}$ provides the expected compound with a moderate yield of $58 \%$ (Entry 8, Table 1). Thus, the hydrophobicity of the cation is probably key to allow for solubilizing the salt in both the organic and aqueous phases. Then, the chlorine anion probably reacts with TMSCN to give the cyanide anion that forms a tight ion-pair with the azaphosphatrane cation and the subsequent attack of the imine function by this cyanide anion leads to the expected product. Nevertheless, as a better yield is obtained with $1 \mathrm{a}$

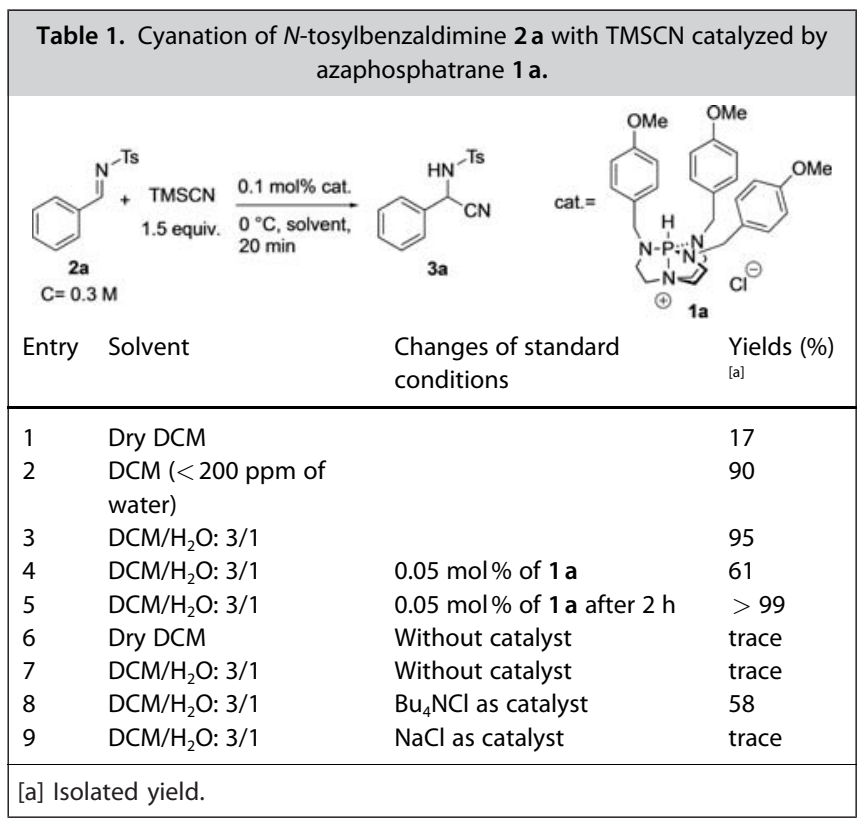

than with the $\mathrm{Bu}_{4} \mathrm{NCl}$ salt, we decided to examine more carefully the exact role played by the azaphosphatrane unit.

Subsequently, we investigated the effect of the acidity of the azaphosphatranes $\mathbf{1} \mathbf{a}-\mathbf{c}$ on the catalytic activity under the optimized conditions, i.e. using the solvent $\mathrm{DCM} / \mathrm{H}_{2} \mathrm{O}: 3 / 1$. We observed a close relation between the $\mathrm{pKa}$ and the yield: the lower the $\mathrm{pKa}$, the higher the yield (Table 2). ${ }^{[1,22]}$ This could be explained by the fact that azaphosphatranes with lower $\mathrm{pKa}$ values are more acidic and therefore better hydrogen bond donors to activate the $\mathrm{C}=\mathrm{N}$ double bond of imines. Thus, two main features of azaphosphatranes can account for the catalytic activity observed: (i) their hydrophobicity allows the counter ion chloride for reacting with the TMSCN in the organic phase (vide infra) and (ii) their hydrogen-bond donor ability, as also evidenced in the conversion of $\mathrm{CO}_{2}$ or in lactide ringopening polymerization, ${ }^{[9]}$ increases the electrophilicity of the imine function. The combination of these two characteristics provide here a remarkable catalyst for the Strecker reaction.

The scope of substrates for the cyanation of imines was performed on representative examples like tosyl-protected imines bearing phenyl groups with different substituents (Entries 1-5, Table 3). The reaction conditions were slightly modified in comparison with those of Table 1 . To take advantage of the high activity of catalyst $1 \mathrm{a}$, only $0.05 \mathrm{~mol} \%$ was used except for the more challenging furan derivative where the reaction was conducted with $2 \mathrm{~mol} \%$. The reaction time was also extended to $2 \mathrm{~h}$. As shown in Table 3, excellent to almost quantitative yields were obtained in all the cases, highlighting the high applicability of $\mathbf{1} \mathbf{a}$ in this reaction.

\begin{tabular}{|lccc|}
\hline \multicolumn{4}{|c|}{ Table 2. Effect of catalyst 1 a-c pKa on the yield. ${ }^{[a]}$} \\
\hline Entry & Catalyst & $\mathrm{pKa}$ in $\mathrm{CH}_{3} \mathrm{CN}$ & Isolated yield (\%) \\
\hline 1 & 1 a & $32.14^{[21]}$ & 95 \\
2 & 1 b & $32.90^{[22]}$ & 65 \\
3 & 1 c & $33.63^{[22]}$ & 19 \\
\hline [a] Reaction conditions: 2a $(0.3 \mathrm{M})$, catalyst (0.1 mol\%), TMSCN (1.5 equiv.), \\
$0^{\circ} \mathrm{C}, 20$ min, $\mathrm{DCM} / \mathrm{H}_{2} \mathrm{O}(3 / 1)$.
\end{tabular}

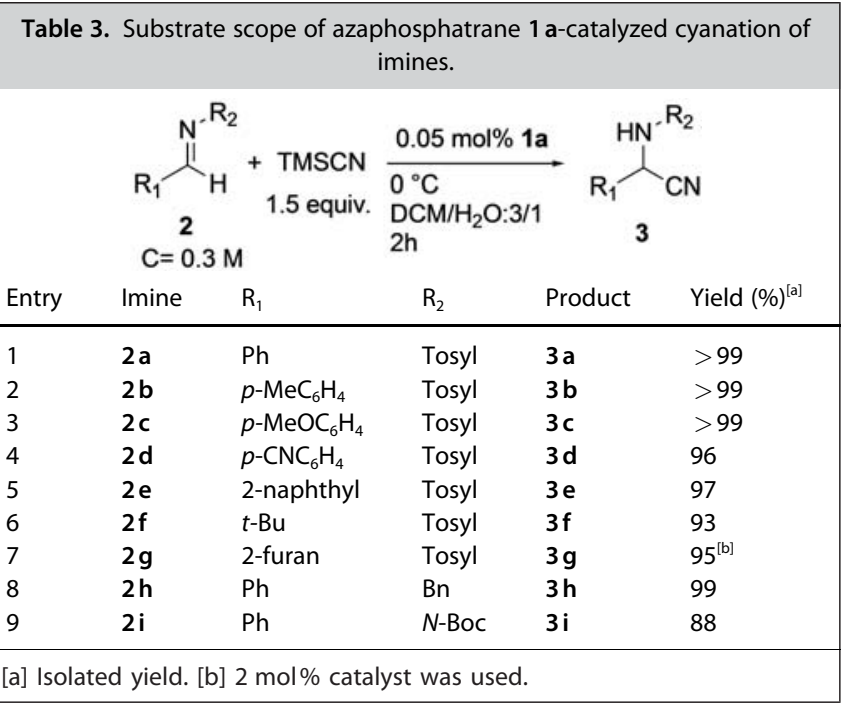


However, when ketimines were used as substrates, no product could be isolated even with $2 \mathrm{~mol} \%$ of catalyst. Changing the protected group $\mathrm{R}_{2}$ did not significantly affect the conversion as high yields were obtained for both groups $\mathrm{Ts}, \mathrm{Bn}$ and $\mathrm{N}$-Boc (Entries 1, 8 and 9, Table 3). The non-aromatic imine $\mathbf{2} f$ seemed to be slightly less reactive but still led to an excellent yield (93\%, Entry 6, Table 3). Using $2 \mathrm{~mol} \%$ of catalyst $1 \mathrm{a}$, the cyanation of an imine bearing a heterocyclic furan group was successfully achieved giving rise to the corresponding product with $95 \%$ yield (Entry 7, Table 3). Compared to most of the other methods previously reported for the Strecker reaction, our procedure allows for a lower catalyst loading and temperature, shorter reaction times, high selectivity (no side reaction is observed) and proves easy to implement: no inert atmosphere and dry solvents are required and the catalyst is airstable and easy to handle. This contrasts sharply with (i) the pro-azaphosphatrane catalyst - also effective for the Strecker reaction - but which is very sensitive to air and water, and therefore more difficult to synthesize and less practical to use as catalyst and (ii) the supported azaphosphatrane nitrate salt which catalyzes the three-component Strecker reaction but with $20 \% \mathrm{~mol}$ of catalyst loading and long reaction times ranging from 15 to 35 hours. ${ }^{[6]}$

A possible reaction pathway is proposed in Scheme 1 to account for these results. The first step would be the reaction of the chloride anion of 1 with TMSCN to give TMSCl and a tight cynanide-azaphosphatrane ion pair. Indeed, upon addition of two equivalents of TMSCN to a solution of $1 \mathrm{a}$ in wet $\mathrm{CD}_{2} \mathrm{Cl}_{2}$, the ${ }^{1} \mathrm{H}$ NMR spectrum shows that TMSOH is formed as expected (Figure S20), but more interestingly, changes in the chemical shift of $1 \mathrm{a}$ are observed: the peaks, corresponding to the $\mathrm{P}-\underline{\mathrm{H}}$ and $\mathrm{C}_{2}-\mathrm{N}$ protons, shift from $5.83 \mathrm{ppm}$ to $5.86 \mathrm{ppm}$ and from $3.51 \mathrm{ppm}$ to $3.42 \mathrm{ppm}$ respectively (Figure S20). Similarly, in the ${ }^{31} \mathrm{P}$ NMR spectrum of $1 \mathrm{a}$, the peak shifts from $-12.25 \mathrm{ppm}$ to $-11.88 \mathrm{ppm}$ (Figure S19). This is consistent with an anion exchange between $\mathrm{Cl}^{-}$and $\mathrm{CN}^{-}$after reaction of

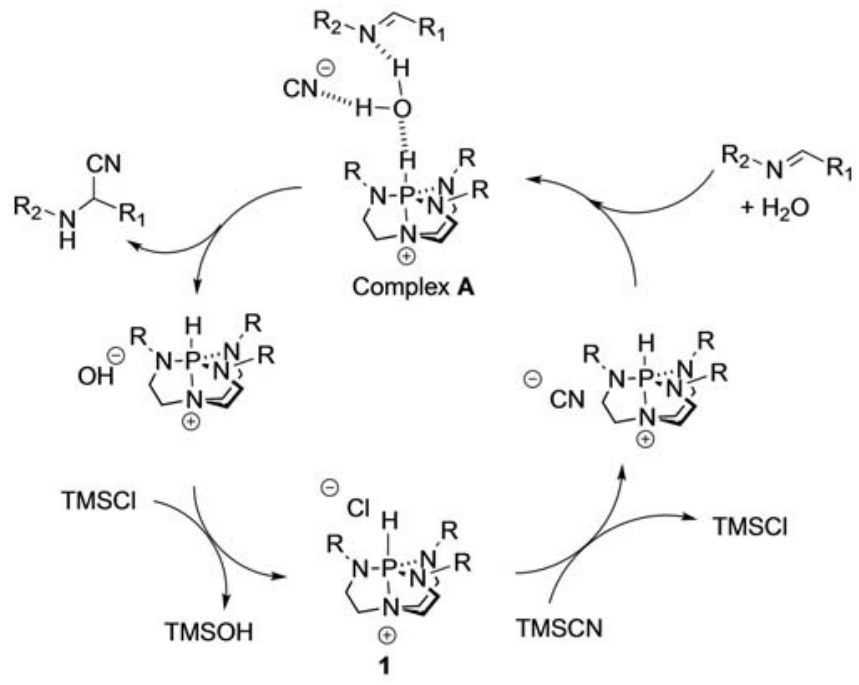

Scheme 1. Proposed mechanism for the cyanation of imines catalyzed by azaphosphatranes.
$\mathrm{Cl}^{-}$with TMSCN especially since the changes in the chemical shifts appears more marked for the protons in the vicinity of the positive charge. Once formed, this cynanide-azaphosphatrane ion pair would then interact with water and the imine through hydrogen bonding, leading to complex $\mathbf{A}^{[23]}$ In this complex water is proposed to bind simultaneously to the three other partners of the reaction (the azaphosphatrane, the cyanide anion and the imine) through three different hydrogen bounds. ${ }^{[23]}$ In agreement with the results obtained in table 2, the increase of the acidity the azaphosphatrane will strengthen its hydrogen bond with water and thus, the subsequent hydrogen bond with imine. Therefore, the cyanide anion will be more prone to attack the activated imine to yield the desired amine product. The ability of 1 a to interact with imines via hydrogen bonding has been investigated: a change in the chemical shift of the $\mathrm{P}-\underline{\mathrm{H}}^{+}$and $\mathrm{CH}_{z}-\mathrm{N}$ protons of $1 \mathrm{a}$ is observed in the ${ }^{1} \mathrm{H}$ NMR spectrum upon addition of one equivalent of imine $2 \mathrm{a}$ in $\mathrm{CD}_{2} \mathrm{Cl}_{2}$ (Figure S21). The peaks corresponding to the $\mathrm{P}-\underline{\mathrm{H}}^{+}$proton are downfield shifted, suggesting a hydrogen bonding with the imine compound. Finally, the hydroxide anion reacts with the previously formed $\mathrm{TMSCl}$ to give TMSOH and the catalyst 1 .

In summary, we have developed a novel methodology to efficiently catalyze cyanation of imines under mild conditions using azaphosphatranes as catalysts. In most cases, high catalytic activity was achieved on tested substrates. Besides, the effect of acidity of catalysts on activity was investigated showing a close relation between the pKa and the yield. Moreover, other chlorine salts were tested, showing lower catalytic activities than azaphosphatranes. These results reveal the key role of both the hydrophobicity and the hydrogen bond donor ability of azaphosphatranes for this reaction.

[1] a) C. Lensink, S.-K. Xi, L. M. Daniels, J. G. Verkade, J. Am. Chem. Soc. 1989, 111, 3478-3479; b) M. A. Laramay, J. G. Verkade, J. Am. Chem. Soc. 1990, $112,9421-9422$.

[2] for a review see: J. G. Verkade, P. B. Kisanga, Tetrahedron 2003, 59, 78197858.

[3] for selected examples: a) J.-S. Tang, J. G. Verkade, Angew. Chem. 1993, 105, 934-936; Angew. Chem. Int. Ed. 1993, 32, 896-898; Angew. Chem. Int. Ed. Engl. 1993, 32, 896-898; b) B. A. D'Sa, J. G. Verkade, J. Org. Chem. 1996, 61, 2963-2966; c) S. Arumugam, J. G. Verkade, J. Org. Chem. 1997, 62, 4827-4828; d) B. A. D'Sa, J. G. Verkade, J. Am. Chem. Soc. 1996, 118, 12832-12833; e) B. A. D'Sa, D. McLeod, J. G. Verkade, J. Org. Chem. 1997, 62, 5057-5061; f) P. Ilankumaran, J. G. Verkade, J. Org. Chem. 1999, 64, 3086-3089.

[4] a) Z. Thammavongsy, J. F. Khosrowabadi Kotyk, C. Tsay, J. Y. Yang, Inorg. Chem. 2015, 54, 11505-11510; b) Z. Thammavongsy, I. M. Kha, J.W. 
Ziller, J. Y. Yang, Dalton Trans. 2016, 45, 9853-9859; c) N. Sutthirat, J. W. Ziller, J. Y. Yang, Z. Thammavongsy, Acta Crystallogr. E75 2019, 438-442; d) Z. Thammavongsy, D. W. Cunningham, N. Sutthirat, R. J. Eisenhart J.W. Ziller, J. Y. Yang, Dalton Trans. 2018, 47, 14101-14110; e) B. Chatelet, P. Nava, H. Clavier, A. Martinez, Eur. J. Inorg. Chem. 2017, 37, 4311-4316.

[5] X. Liu, J. G. Verkade, J. Org. Chem. 2000, 64, 4840-4843.

[6] B. M. Fetterly, N. K. Jana, J. G. Verkade, Tetrahedron, 2006, 62, 440-456.

[7] P. Dimitrov-Raytchev, J.-P. Dutasta, A. Martinez, A. ChemCatChem 2012, 4, 2045-2049.

[8] D. Zhang, D. Jardel, F. Peruch, N. Calin, V. Dufaud, J.-P. Dutasta, A Martinez, B. Bibal, Eur. J. Org. Chem. 2016, 2016, 1619-1624.

[9] a) B. Chatelet, L. Joucla, J.-P. Dutasta, A. Martinez, K. C. Szeto, V. Dufaud J. Am. Chem. Soc. 2013, 135, 5348-5351; b) B. Chatelet, L. Joucla, J.-P. Dutasta, A. Martinez, V. Dufaud, Chem. Eur. J. 2014, 20, 8571-8574; C) B. Chatelet, E. Jeanneau, J.-P. Dutasta, V. Robert, A. Martinez, V. Dufaud, Catal. Commun. 2014, 52, 26-30.

[10] B. Chatelet, L. Joucla, J.-P. Dutasta, A. Martinez, V. Dufaud, J. Mater. Chem. 2014, 2, 14164-14172.

[11] D. Zhang, T. K. Ronson, J. Mosquera, A. Martinez, J. R. Nitschke, Angew. Chem. 2018, 130, 3779-3783; Angew. Chem. Int. Ed. 2018, 57, 3717-3721 Angew. Chem. Int. Ed. 2018, 57, 3717-3721; Angew. Chem. 2018, 130, 3779-3783.

[12] A. D. Matthews, S. Prasad, N. D. Schley, K. J. Donald, M. W. Johnson, Inorg. Chem. 2019, 58, 15983-15992.

[13] a) P. L. Feldman, M. F. Brackeen, J. Org. Chem. 1990, 55, 4207-4209; b) A. J. Walz, F. L. Hsu, Tetrahedron Lett. 2014, 55, 501-502; c) F. G. Zhang, X. Y. Zhu, S. Li, J. Nie, J. A. Ma, Chem. Commun. 2018, 48, $11552-$ 11554; d) A. Sadhukhan, S. Saravanan, N. U. H. Khan, R. I. Kureshy, S. H. Abdi, S. H. C. Bajaj, J. Org. Chem. 2012, 77, 7076-7080; e) C. Bolm, R. Mocci, C. Schumacher, M. Turberg, F. Puccetti, J. G. Hernandez, Angew. Chem. 2018, 130, 2447-2450; Angew. Chem. Int. Ed. 2018, 57, 2423-2426;
Angew. Chem. Int. Ed. 2018, 57, 2423-2426; Angew. Chem. 2018, 130 2447-2450.

[14] For review, see: V. V. Kouznetsov, C. E. P. Galvis, Tetrahedron 2018, 74, 773-810.

[15] a) S. K. De, R. A. Gibbs, Tetrahedron Lett. 2004, 45, 7407-7408; b) Z. L. Shen, S. J. Ji, T. P. Loh, Tetrahedron 2008, 64, 8159-8163; c) S. K. De, Synth. Commun. 2005, 35, 653-656; d) S. K. De, J. Mol. Catal. A 2005, 225, 169-171; e) M. Narasimhulu, T. S. Reddy, K. C. Mahesh, S. M. Reddy, A. V. Reddy, Y. Venkateswarlu, J. Mol. Catal. A 2007, 264, 288-292; f) S. Kobayashi, H. Ishitani, M. Ueno, Synlett 1997, 115-116; g) S. Kobayashi, T. Busujima, Chem. Commun. 1998, 981-982; h) A. S. Paraskar, A. Sudalai, Tetrahedron Lett. 2006, 47, 5759-5762.

[16] a) Y. Fukuda, Y. Maeda, K. Kondo, T. Aoyama, Synthesis 2006, 12, 19371939; b) Y. Fukuda, K. Kondo, T. Aoyama, Synthesis 2006, 16, 2649-2652.

[17] A. Heydari, A. Arefi, S. Khaksar, R. K. Shiroodi, J. Mol. Catal. A 2007, 271 $142-144$.

[18] a) M. S. Sigman, P. Vachal, E. N. Jacobsen, Angew. Chem. 2000, 112, 1336-1338; Angew. Chem. Int. Ed. 2000, 39, 1279-1281; Angew. Chem. Int. Ed. 2000, 39, 1279-1281; Angew. Chem. 2000, 112, 1336-1338; b) S. C. Pan, B. List, Synlett 2007, 317, 318-320.

[19] W.-B. Wu, X.-P. Zeng, J. Zhou, J. Org. Chem. 2020, in press, DOI: 10.1021/ acs.joc.9b03347.

[20] J. Yang, B. Chatelet, F. Ziarelli, V. Dufaud, D. Hérault, A. Martinez, Eur. J. Org. Chem. 2018, 45, 6328-6332.

[21] P. Dimitrov Raytchev, A. Martinez, H. Gornitzka, J.-P. Dutasta, J. Am. Chem. Soc. 2011, 133, 2157-2159.

[22] P. B. Kisanga, J. G. Verkade, R. Schwesinger J. Org. Chem. 2000, 65, 54315432.

[23] J. Taillades, A. Commeyras, Tetrahedron 1974, 30, 2493-2501. 